\title{
Estratégias de interação entre tutor e estudantes em Educação a Distância
}

\author{
Querte Mehlecke ${ }^{1}$ \\ Alda Pereira $^{2}$ \\ Liane Tarouco ${ }^{3}$
}

\section{Resumo}

Este artigo apresenta os dados preliminares de um projecto de investigação em sua fase inicial. A partir de um inquérito respondido por estudantes do Seminário de um curso de graduação, da Universidade Aberta, Portugal, faz-se uma análise dos dados de algumas respostas às questões norteadoras da investigação no que se refere à interacção entre o professor e os estudantes, bem como sobre o papel do tutor na modalidade a distância.

Palavras-Chave: Educação a distância, tutor, interacção

\section{Interaction strategies between tutor and students in Distance Education}

\begin{abstract}
This article aims at presenting the preliminary findings of an investigation project in its initial stage. Based on a questionnaire answered by the Seminary students linked to a graduate course at the Open University, Portugal, a data analysis of some of the answers to key questions has been performed, specially referring to the interaction between students and teacher as well as the role of the tutor in the distance learning modality.
\end{abstract}

Keywords: Distance Education. Interaction Strategies. Tutor Role. Project.

\section{Apresentação: Seminário Fase 1}

Este artigo aborda os primeiros resultados estudo situa-se na parte inicial de um projecto de investigação que visa o estudo das metodologias e formas de interacção docente-aprendente e aprendente-aprendente em regime de ensino a distância, no âmbito de seminários abertos, isto é, seminários que visam a concepção, por parte dos professores em formação, de projectos de intervenção educacional.

Estes seminários são frequentados pelos estudantes do Curso de Complemento de Formação Científica e Pedagógica para Professores do $1^{\circ}$ Ciclo do Ensino Básico e do Curso de Complemento de Formação Científica e Pedagógica para Educadores de Infância - modalidade a distância, Universidade Aberta, Portugal. Para além de um conjunto de disciplinas estruturadas segundo campos de saber específicos, os alunos frequentam uma disciplina, não estruturada, onde é suposto o estudante aprofundar de forma autónoma um dado problema ou conceber um projecto de intervenção no terreno. É no contexto dessa disciplina, desenvolvida em regime de seminário que os estudantes, professores e educadores de infância, se debruçam sobre a sua realidade escolar e procuram articular de forma coerente e reflexiva a teoria e a prática profissional.

Como forma de apoio indirecto os alunos dispõem de um pequeno livro, onde são abordados algumas questões estruturantes e onde se aponta os objectivos o seminário. Os estudantes são para isso organizados em grupos de 20 alunos, no máximo, e são apoiados por um professor/tutor.

\footnotetext{
${ }^{1}$ Doutoranda do Programa de Pós-Graduação em Informática na Educação, Universidade Federal do Rio Grande do Sul, Porto Alegre, Brasil. Professora da FACCAT, Taquara, RS, Brasil. Bolsista CAPES querte@ faccat.br

${ }^{2}$ Professora Doutora do Departamento de Ciências da Educação, Universidade Aberta, Portugal. amp@ univ-ab.pt

${ }^{3}$ Professora Doutora do Programa de Pós-Graduação em Informática na Educação, Universidade Federal do Rio Grande do Sul, Porto Alegre, Brasil.

V. $3 \mathrm{~N}^{\circ} 1$, Maio, 2005
} 
Pereira e Miranda (2003) conceituam Seminário como "projecto ou desenvolvimento experimental, doravante designado apenas por Seminário, tem como finalidade constituir um espaço de reflexão e acção prática conducente a um desempenho fundamentado e profissionalmente mais eficaz por parte do estudante, professot/educador em formação.” (p.11)

São objectivos específicos desta investigação:

a) identificar metodologias de ensino a distância adequadas à concepção autónoma de projectos educacionais;

b) compreender os mecanismos que subjazem ao desenvolvimento da autonomia do estudante em regime de ensino a distância no processo de (re)construção de saberes e de desenvolvimento de competências;

c) construir novos referentes teórico-metodológicos em função do público-alvo deste projecto; e

d) identificar indicadores de qualidade aplicáveis no contexto desses seminários.

A partir destes objetivos, apresentam-se neste artigo três pontos de estudo:

$1^{\circ}$.) As interações do tutor com os estudantes expressas nos diferentes meios de comunicação;

$2^{\mathbf{o}}$.) As dificuldades apresentadas no decorrer do seminário, a partir do levantamento dos dados e instrumento de recolha de dados;

$3^{\circ}$.) $\mathrm{O}$ uso do livro de apoio ao Seminário: Problemas e Projectos Educacionais.

\section{A Comunicação entre Tutor e Estudante}

Segundo Bakhtin (2000), toda atividade humana está relacionada com a utilização da língua, por mais variada que seja seu uso. Neste sentido, as interações entre tutor e estudante, no Seminário, ocorreram de duas formas: uma, oral, através do uso do telefone, meio pelo qual os estudantes entravam em contacto com o tutor para esclarecer dúvidas sobre o desenvolvimento do projecto; outra, através do uso de mensagens eletrônicas (o email), recurso também utilizado para solicitar esclarecimentos de dúvidas através de mensagens escritas. Tanto numa quanto noutra forma de comunicação, o objetivo era entrar em contacto com o tutor para solicitar ajuda referente as dúvidas que iam surgindo no desenvolvimento do projecto.

Landim (1997) destaca as vantagens no uso do telefone na tutoria. A seguir, apresenta-se algumas delas:

- Oportunidade de discutir os pontos de vista que vão surgindo no desenvolvimento das atividades;

- Atingir uma população que não teria acesso ao ensino presencial;

- Possibilitar atendimento personalizado aos estudantes;

- Promover confiabilidade ao dar o devido destaque às dúvidas de cada aluno em particular.

De acordo com as vantagens apresentadas por Landim, pode-se verificar no quadro 1 o resultado do inquérito respondido por 88 estudantes do Seminário, no que diz respeito à questão que se refere ao uso do telefone como meio utilizado para a comunicação com o tutor, que está de acordo com as vantagens apresentadas.

\begin{tabular}{lcccccc}
\hline Acção & $\begin{array}{c}\text { Não } \\
\text { concorda }\end{array}$ & $\begin{array}{c}\text { Concorda } \\
\text { pouco }\end{array}$ & Concorda & $\begin{array}{c}\text { Concorda } \\
\text { muito }\end{array}$ & Desacordo & Acordo \\
\hline $\begin{array}{l}\text { Interpelação do tutor } \\
\text { mais rápida }\end{array}$ & 0 & 3,4 & 53,4 & 43,2 & 3,4 & 96,6 \\
mais fácil colocar & 1,1 & 9,1 & 44,3 & 44,3 & 10,2 & 88,6 \\
\hline
\end{tabular}




\begin{tabular}{lcccccc}
\hline questões & & & & & & \\
dá menos trabalho & 6,8 & 26,1 & 33 & 28,4 & 32,9 & 61,4 \\
estou mais à vontade & 3,4 & 15,9 & 43,2 & 34,1 & 19,3 & 77,3 \\
$\begin{array}{l}\text { entendo melhor } \\
\begin{array}{l}\text { oralmente } \\
\text { não estou disponível } \\
\text { para email }\end{array}\end{array}$ & 4,5 & 11,4 & 31,8 & 51,1 & 15,9 & 82,9 \\
\hline
\end{tabular}

Quadro 1: o uso do telefone

De acordo com os resultados percebe-se que $96 \%$ dos estudantes dizem que o uso do telefone é a forma mais rápida de interpelação com o tutor. Entretanto $88 \%$ diz que é mais fácil colocar as questões por telefone e $82,9 \%$ diz que entende melhor as explicações do professor quando dadas oralmente. Observa-se que, de modo geral, $74,6 \%$ dos estudantes têm acesso ao email e, mesmo assim, preferem a comunicação com o tutor por telefone. Neste caso, os resultados confirmam que os estudantes preferem o uso do telefone, pois, de acordo com o resultado do inquérito, dizem que a interpelação do tutor é mais rápida. O telefone é, de acordo com os dados levantados, o meio mais utilizado pelos estudantes e tutores para comunicação, seguido do correio eletrônico, neste estudo. O tutor utiliza o telefone para contacto com o estudante tanto para tirar as dúvidas que surgem como também para motivá-lo e não perder o contacto com ele. Aretio (2001) corrobora ao dizer que o telefone é um meio de comunicação recomendável pois permite uma relação interpessoal com a mesma agilidade que aconteceria numa aula presencial e também porque nestes contactos telefónicos podem ser resolvidos problemas pontuais e também gerar novas idéias e reflexões.

Nesse sentido, as evidências confirmam que os estudantes sentem-se melhor ao usar o telefone. Surge aqui uma necessidade de diálogo onde podem eles questionar, interagir e esclarecer as dúvidas surgidas no desenvolvimento do projecto. $\mathrm{O}$ uso do telefone pelo estudante demonstra a necessidade de estabelecer relações de proximidade com o tutor pelo diálogo. Faraco (2003) afirma que todo o dizer é orientado para a resposta e é eternamente dialogizado.

Por outro lado, o uso de mensagens eletrônicas (email) foi utilizado por alguns estudantes para a comunicação com o tutor. O quadro 2 apresenta o resultado da questão sobre o uso do email, uma das questões do inquérito aplicado aos estudantes.

\begin{tabular}{lcccccc}
\hline Acção & $\begin{array}{c}\text { Não } \\
\text { concorda }\end{array}$ & $\begin{array}{c}\text { Concorda } \\
\text { pouco }\end{array}$ & Concorda & $\begin{array}{c}\text { Concorda } \\
\text { muito }\end{array}$ & Desacordo & Acordo \\
\hline permite sistematizar melhor & 2,3 & 31,8 & 25 & 9,1 & 34,1 & 34,1 \\
permite melhor gestão do tempo & 3,4 & 26,1 & 27,3 & 9,1 & 29,5 & 36,4 \\
$\begin{array}{l}\text { permite maior rapidez de } \\
\text { feedback }\end{array}$ & 10,2 & 25 & 27,3 & 4,5 & 35,2 & 31,8 \\
$\begin{array}{l}\text { obriga-me a cuidar melhor da } \\
\text { mensagens }\end{array}$ & 8 & 15,9 & 29,5 & 13,6 & 23,9 & 43,1 \\
$\begin{array}{l}\text { permite um registo permanente } \\
\begin{array}{l}\text { não me esqueço de colocar } \\
\text { questões }\end{array}\end{array}$ & 2,3 & 4,5 & 34,1 & 26,1 & 6,8 & 60,2 \\
\hline
\end{tabular}

Quadro 2: o uso do email

Como se pode observar, o uso do email nesta fase do Seminário não foi tão significativa quanto o uso do telefone. Nesse quadro, 60,2\% dos estudantes dizem que o uso das mensagens eletrônicas permite o registro permanente do contacto com o tutor e $51,1 \%$ dizem que o uso do email permite que eles não esqueçam de colocar as questões.

A análise dos resultados do uso do telefone e do email conduz à reflexão: se apenas $36,4 \%$ dos estudantes não estão disponíveis ao uso de email, então o que V. $3 \mathrm{~N}^{\circ}$ 1, Maio, 2005 
acontece, será por ser o telefone mais cômodo de usar ao invés do email? Será que o domínio tecnológico não é suficiente para poder utilizá-lo? Será que o tutor prefere o telefone ao email e por isso não motiva os estudantes a utilizarem? Ou qual será o real motivo de preferirem utilizar o telefone em lugar do email?

Ao buscar-se responder estas questões, Faraco (2003) parece apontar a uma possível saída ao dizer que "compreender não é um ato passivo, mas uma réplica ativa, uma resposta, uma tomada de posição diante do texto".

Com vistas à compreensão estabelecida através das tensões nas relações dialógicas possibilitadas pelas tecnologias, tem-se que $82,9 \%$ dos estudantes afirmam compreender melhor o tutor quando dialogam com ele por telefone.

Nossa hipótese aqui é que através do diálogo oral, por telefone, a compreensão é mais significativa. Vale lembrar que nessa fase - Seminário, Fase 1 - os meios de comunicação utilizados foram somente o telefone e o email.

Estar em contacto com os diversos recursos das tecnologias da comunicação e informação não é exatamente saber usá-los para fins pedagógicos. Conforme o resultado apresentado nessas duas questões, que fazem parte de um contexto pedagógico, pode-se dizer que o uso do telefone propicia uma comunicação dialógica entre estudantes e tutor, pois ao falar com o outro as pessoas organizam mentalmente suas questões: se não se fazem entender, mudam logo a forma de perguntar e/ou explicar. Já quanto que o uso do email este requer uma elaboração maior tanto na formulação da escrita quanto no retorno da resposta. Isso demanda tempo, o tempo de escrever, o tempo de enviar, o tempo do recebimento e o tempo de retorno. Nesse sentido, o estudante prefere o telefone uma vez que a resposta é decorrente de uma interação de diálogo bem mais rápida. Voloshinov apud Faraco(2003), corrobora afirmando que a interação é entendida como "toda a comunicação verbal, de qualquer tipo que seja", sendo o diálogo face-a-face apenas um deste muitos tipos.(p. 106) E é nesse contexto que a interação estudante/tutor ocorre, não face-a-face mas de um encontro de vozes que dialogam por meio do telefone.

O uso do telefone como meio de interação entre estudante e professor é apenas um dos muitos recursos da educação a distância. Aretio (1994), afirma que "O Ensino a Distância é um sistema tecnológico de comunicação bidirecional, que pode ser massivo e que substitui a interação pessoal, na sala de aula, de professor e aluno, como meio preferencial de ensino, pela ação sistemática e conjunta de diversos recursos didáticos e pelo apoio de uma organização e tutoria que propiciam a aprendizagem independente e flexível dos alunos."

Até aqui se falou da comunicação bidirecional entre tutor/estudante e estudante/tutor. Nessa fase não ocorreu interação entre as pessoas do grupo, apenas uma relação verbal de um para um, pois os recursos utilizados não permitiram as trocas dialógicas entre os participantes apenas entre estudante e professor.

\section{O papel do Professor/Tutor no Seminário}

De acordo com o regime de Seminário adoptado, o tutor é o professor responsável pelo Seminário. Segundo Landim(1997) "tutor é o elemento importante e indispensável na rede de comunicação que vincula os cursistas à instituição de ensino promotora do curso, pois, além de manter a motivação dos alunos, possibilita a retroalimentação acadêmica e pedagógica do processo educativo (p. 125)." O contacto com o tutor no Seminário a distância dá-se a partir das necessidades apresentadas pelos estudantes, que, situando-se no contexto da sua realidade imediata, procuram desenvolver um plano pedagógico de intervenção(projecto). Nessa modalidade de 
ensino a distância, os recursos comunicacionais mais comummente utilizados, tais como o telefone e o e-mail, intermedeiam o diálogo entre tutor e estudantes.

Nessa visão, o papel do tutor/professor se solidifica, sendo ele aquele que dialoga, orienta, tira dúvidas, estimula, provoca, acompanha e se faz presente na construção do conhecimento dos estudantes mesmo distantes fisicamente.

O tutor caracteriza-se por seu papel solidário, aberto, paciente e sempre disposto a ouvir as dúvidas, desabafos e comentários dos estudantes. Ao agir dessa forma, possibilita o relacionamento entre o "eu" tutor e o "tu" estudante. Fala-se nesse artigo do "eu" tutor e do "tu" estudante por ser o primeiro Seminário de investigação que utilizou apenas recursos comunicacionais como o telefone e o email.

Dentre as questões respondidas pelos estudantes no inquérito já referenciado, o quadro 2 apresenta um registo de como os estudantes sentiram a presença do tutor no decorrer do Seminário. E, para melhor compreender o desempenho do tutor na visão dos estudantes, o quadro 2 apresenta o resultado de uma das questões do inquérito respondido pelos estudantes no que se refere ao papel do tutor.

\begin{tabular}{|c|c|c|c|c|c|c|}
\hline Acção & $\begin{array}{l}\text { Não } \\
\text { concorda }\end{array}$ & $\begin{array}{l}\text { Concorda } \\
\text { pouco }\end{array}$ & Concorda & $\begin{array}{l}\text { Concorda } \\
\text { muito }\end{array}$ & Desacordo & Acordo \\
\hline disponível para ouvir & 0 & 0 & 14,8 & 84,1 & 0 & 98,9 \\
\hline $\begin{array}{l}\text { disponível para discutir } \\
\text { questões colocadas }\end{array}$ & 0 & 1,1 & 15,9 & 81,8 & 1,1 & 97,7 \\
\hline $\begin{array}{l}\text { preocupado com os meus } \\
\text { problemas }\end{array}$ & 0 & 6,8 & 28,4 & 60,2 & 6,8 & 88,6 \\
\hline $\begin{array}{l}\text { empenhado em resposta } \\
\text { rápida }\end{array}$ & 0 & 2,3 & 28,4 & 65,9 & 2,3 & 94,3 \\
\hline paciente nos contactos & 0 & 2,3 & 23,9 & 72,7 & 2,3 & 96,6 \\
\hline $\begin{array}{l}\text { justo nas apreciações sobre } \\
\text { o trabalho }\end{array}$ & 0 & 3,4 & 31,8 & 59,1 & 3,4 & 90,9 \\
\hline
\end{tabular}

\section{Quadro 2: O Tutor}

De acordo com o resultado apresentado no quadro 2, acima, os estudantes demonstraram grande satisfação quanto ao atendimento do tutor, pois esteve ele sempre disponível durante o período de desenvolvimento dos planos e projectos do Seminário. Ressalta-se nesse momento a importância que os estudantes deram para a questão da disponibilidade do tutor em ouvi-los, ratificando ser o papel do tutor indispensável para o processo de ensino e aprendizagem a distância. Em acréscimo, a necessidade de diálogo que os estudantes manifestaram sentir constitui-se como um outro aspecto a se destacar. O tutor foi paciente, ouviu e discutiu as questões levantadas pelos estudantes, demonstrando preocupação com os estudantes. Nesse quadro percebe-se a mais valia do papel do tutor pois se não estivesse disposto a ouvir e discutir os problemas dos estudantes os resultados poderiam ser outros.

Independente do recurso que o tutor utilizou para se comunicar com os estudantes, vale salientar que sua estratégia atendeu as necessidades dos estudantes, contribuindo para a construção do conhecimento, objectivo maior desse Seminário. Isso, em última instância, é o que realmente importa no processo de tutoria em educação a distância. Quanto aos meios utilizados pelo tutor, telefone, email e outros, na verdade, foram apenas meios. Importante mesmo é encontrar formas ou estratégias para que o estudante distante não fique sem apoio e sem possibilidade de produzir solução para seus problemas e dúvidas. Os recursos foram alternativos, de acordo com $o$ conhecimento, possibilidades e necessidades de cada um. Todos eles, se bem utilizados, atendem as necessidades de uma tutoria em $\mathrm{EaD}$. É importante salientar que os recursos 
utilizados devem estar de acordo com o perfil dos usuários, deve buscar atender senão a todos, pelo menos à maioria, seja por um meio ou outro.

$\mathrm{Na}$ sequência, apresenta-se o quadro 3 que aponta os resultados do inquérito da questão: "feedback do tutor ajudou-me a ....".

Os dados apresentados no quadro 3 complementam os dados relacionados no quadro 2, pois não resolve apenas o tutor estar disponível, responder questões, ser acessível se não atender às reais necessidades dos estudantes. Assim, o quadro 3 busca revelar o que resultou da paciência para ouvir discussões e esclarecimentos das dúvidas dos estudantes, em suma, apresenta o feedback do tutor, com resultados em percentagem.

\begin{tabular}{|c|c|c|c|c|c|c|}
\hline Acção & $\begin{array}{c}\text { Não } \\
\text { concorda }\end{array}$ & $\begin{array}{l}\text { Concorda } \\
\text { pouco }\end{array}$ & Concorda & $\begin{array}{c}\text { Concorda } \\
\text { muito }\end{array}$ & Desacordo & Acordo \\
\hline $\begin{array}{l}\text { a elaborar o plano de } \\
\text { trabalho }\end{array}$ & 4,5 & 2,3 & 50 & 38,6 & 6,8 & 88,6 \\
\hline $\begin{array}{l}\text { a escolher o tipo } \\
\text { trabalho }\end{array}$ & 20,5 & 22,7 & 36,4 & 13,6 & 43,2 & 50 \\
\hline $\begin{array}{l}\text { a encontrar bibliografia } \\
\text { específica }\end{array}$ & 6,9 & 18,2 & 47,7 & 19,3 & 25,1 & 67 \\
\hline $\begin{array}{l}\text { a delimitar âmbito do } \\
\text { trabalho }\end{array}$ & 2,3 & 5,7 & 55,7 & 25 & 8 & 80,7 \\
\hline $\begin{array}{l}\text { a definir aspectos } \\
\text { práticos }\end{array}$ & 9,1 & 8 & 52,3 & 20,5 & 17,1 & 72,8 \\
\hline $\begin{array}{l}\text { a reflectir sobre } \\
\text { fundamentação }\end{array}$ & 4,5 & 11,4 & 61,4 & 15,9 & 15,9 & 77,3 \\
\hline $\begin{array}{l}\text { a seleccionar } \\
\text { metodologia do } \\
\text { trabalho }\end{array}$ & 3,4 & 12,5 & 50 & 22,7 & 15,9 & 72,7 \\
\hline a definir o problema & 6,8 & 18,2 & 45,5 & 23,9 & 25 & 69,4 \\
\hline $\begin{array}{l}\text { a preparar apresentação } \\
\text { oral }\end{array}$ & 14,8 & 21,6 & 38,6 & 14,8 & 36,4 & 53,4 \\
\hline $\begin{array}{l}\text { a ver aspectos mal } \\
\text { equacionados }\end{array}$ & 4,5 & 12,5 & 45,5 & 30,7 & 17 & 76,2 \\
\hline a formular objectivos & 8 & 25 & 45,5 & 10,2 & 33 & 55,7 \\
\hline $\begin{array}{l}\text { a reflectir sobre prob. } \\
\text { educativos }\end{array}$ & 5,7 & 25 & 52,3 & 8 & 30,7 & 60,3 \\
\hline $\begin{array}{l}\text { a desmontar ideias } \\
\text { prévias }\end{array}$ & 9,1 & 15,9 & 62,5 & 5,7 & 25 & 68,2 \\
\hline a sistematizar idéias & 2,3 & 11,4 & 64,8 & 13,6 & 13,7 & 78,4 \\
\hline $\begin{array}{l}\text { a desenvolver reflexão } \\
\text { pessoal }\end{array}$ & 6,8 & 21,6 & 44,3 & 19,3 & 28,4 & 63,6 \\
\hline a re-orientar trabalho & 4,5 & 9,1 & 48,9 & 28,4 & 13,6 & 77,3 \\
\hline $\begin{array}{l}\text { Feed ajudou a manter } \\
\text { interesse }\end{array}$ & 1,1 & 5,7 & 52,3 & 35,2 & 6,8 & 87,5 \\
\hline $\begin{array}{l}\text { Feed ajudou a superar } \\
\text { dificuldades }\end{array}$ & 1,1 & 8 & 40,9 & 46,6 & 9,1 & 87,5 \\
\hline
\end{tabular}

\section{Quadro 3 - O feedback do tutor}

É notável que a educação a distância esteja em permanente processo e que cada instituição esteja buscando novas metodologias e estratégias para o ensino a distância. $\mathrm{O}$ processo de comunicação entre estudante/tutor - tutor/estudante é o que marca esse processo. Nessa perspectiva, Aretio (2001) apresenta estratégias que o tutor deve desenvolver em sua prática para alcançar bons resultados com os estudantes. Isso se pode constatar no quadro 3 , no tocante às estratégias utilizadas pelo tutor, em destaque abaixo: 
- 88,6 dos estudantes concordam que o feedbak do tutor contribuiu para elaboração do plano de trabalho;

- 80,7 dos estudantes afirmam que o tutor ajudou-os a delimitar o âmbito do trabalho;

- 87,5 dos estudantes afirmam que o tutor ajudou-os a manter o interesse pelo trabalho;

- 87,5 dos estudantes afirmam que o tutor ajudou-os a superar as dificuldades no decorrer do trabalho.

Nesse contexto, os estudantes estabeleceram um processo de interação com o tutor e procuraram o meio comunicacional que mais sentiam-se a vontade com o tutor.

O apoio aos estudantes não se deu apenas através do contacto com o tutor, eles utilizaram o manual: "Problemas e Projectos Educacionais", que apresenta claramente todos os passos para o desenvolvimento do Projeto.

Tendo em vista a preocupação com a construção do conhecimento como o diferencial dessa e das outras fases do Seminário, no ponto a seguir apresentam-se dados relativos ao uso do manual Problemas e Projectos Educacionais.

\section{O uso do texto de apoio ao Seminário}

No texto Problemas e Projectos Educacionais procura-se orientar os estudantes no desenvolvimento de projectos. Esse texto está dividido em duas partes apresentados por Pereira e Miranda (2003):

Primeira parte:

Contém os Fundamentos onde são explicados alguns conceitos essenciais e são enunciados alguns aspectos importantes para auxiliar o estudante a reflectir sobre o trabalho que se pretende que todos os estudantes realizem.

Segunda parte:

Trata-se do Manual do estudante que são enunciados os objectivos que deverão nortear o Seminário, definidas as modalidades de trabalho a realizar, enunciados os desempenhos desejados por parte do estudante e definidos os critérios de avaliação dos produtos finais. Constitui, por isso, um guião de orientação do Seminário.

Pereira e Miranda (2003), ao apresentar o texto Problemas e Projectos Educacionais, dizem que ele: "Se destina a ser utilizado pelos estudantes do Curso de Complemento de Formação Científica e Pedagógicas para Professores do $1^{\circ}$ Ciclo do Ensino Básico e do Curso de Complemento de Formação Científica e Pedagógica para Educadores de Infância, no âmbito do Seminário, Projecto ou Desenvolvimento Experimental." (p.11)

Ao ser o manual o instrumento impresso de apoio ao estudante, este não substitui o apoio do tutor. Enquanto manual, o texto apresenta conceitos e fundamenta todas as questões voltadas para o desenvolvimento do plano (projeto), não apresentando, contudo, nenhum exemplo de projecto já elaborado. Para a elaboração do projecto, $97,7 \%$ dos estudantes leram e analisaram o manual e no desenvolvimento do projecto solicitaram a ajuda do tutor.

Os dados do quadro 4 representam a utilização do texto Problemas e Projectos Educacionais e quanto ele foi indispensável no desenvolvimento do projecto.

\begin{tabular}{lrrrrrr}
\hline Acção & $\begin{array}{l}\text { Não } \\
\text { concorda }\end{array}$ & $\begin{array}{l}\text { Concorda } \\
\text { pouco }\end{array}$ & Concorda & $\begin{array}{l}\text { Concorda } \\
\text { muito }\end{array}$ & Desacordo & Acordo \\
\hline escolher tipo trabalho & 9,1 & 10,2 & 44,3 & 34,1 & 19,3 & 78,4 \\
estabelecer plano & 0 & 8 & 54,5 & 36,4 & 8 & 90,9 \\
definir problema & 5,7 & 20,5 & 44,3 & 27,3 & 26,2 & 71,6 \\
\hline
\end{tabular}




\begin{tabular}{|c|c|c|c|c|c|c|}
\hline \multicolumn{4}{|l|}{ Novas Tecnologias na Educação } & \multicolumn{2}{|c|}{ CINTED-UFRGS } & \\
\hline delimitar aspectos trabalho & 0 & 11,4 & 62,5 & 23,9 & 11,4 & 86,4 \\
\hline definir aspectos práticos & 3,4 & 15,9 & 61,4 & 15,9 & 19,3 & 77,3 \\
\hline preparar apresentação oral & 18,2 & 40,9 & 34,1 & 4,5 & 59,1 & 38,6 \\
\hline definir metodologia trabalho & 1,1 & 19,3 & 67 & 11,4 & 20,4 & 78,4 \\
\hline entender parâmetros avaliação & 0 & 8 & 63,6 & 25 & 8 & 88,6 \\
\hline entender importância projectos & 0 & 10,2 & 65,9 & 18,2 & 10,2 & 84,1 \\
\hline avaliar o trabalho & 3,4 & 20,5 & 61,4 & 10,2 & 23,9 & 71,6 \\
\hline $\begin{array}{l}\text { estabelecer cronograma de } \\
\text { trabalho }\end{array}$ & 4,5 & 23,9 & 62,5 & 6,8 & 28,4 & 69,3 \\
\hline estruturar trabalho & 0 & 13,6 & 64,8 & 17 & 13,6 & 81,8 \\
\hline $\begin{array}{l}\text { compreender natureza } \\
\text { seminário }\end{array}$ & 0 & 9,1 & 63,6 & 26,1 & 9,1 & 89,7 \\
\hline fundamentar minha prática & 0 & 21,6 & 58 & 17 & 21,6 & 75 \\
\hline
\end{tabular}

\section{Quadro 4 - o uso do texto Problemas e Projectos Educacionais}

O quadro mostra que $90,9 \%$ dos estudantes estavam de acordo que o referido texto os ajudou a estabelecer o plano (projeto). De modo geral, o texto atendeu às expectativas dos estudantes, pois além desse instrumento havia a disponibilidade do tutor para tirar as dúvidas quando surgiam. Para $89,7 \%$ dos estudantes, o manual ajudou a entender a natureza do Seminário.

De modo geral, 97,7\% do grupo analisou o manual Problemas e Projectos Educacionais para a elaboração do plano. Outros $63,6 \%$ dos estudantes solicitaram ajuda de colegas. Esse dado mostra que a interação com outras pessoas se torna necessária, sendo o tutor o contacto directo principal. Em acréscimo, como pode-se observar no quadro 4 , além do tutor, $42 \%$ do grupo procurou a ajuda de outros profissionais.

Neste contexto, pode-se afirmar que além do texto escrito e do apoio do tutor, os estudantes sentiram necessidade de buscar ajuda de com outras pessoas. É da natureza humana viver em comunidades, dialogar, trocar idéias e ser solidário. Isso aponta para um outro modo de conviver (real e virtual) em que cada vez mais se fortalecem os grupos/comunidades distantes as quais desenvolvem seus trabalhos com a ajuda de diversos meios/recursos e pessoas com os mesmos objetivos e trabalhos comuns.

Mesmo que a maioria dos estudantes preferisse o contacto direto com o tutor através do telefone e não por email, $65,9 \%$ utilizou a Internet como fonte de pesquisa, sinal de que não usuários dos recursos tecnológicos, mas precisam da voz "viva" do tutor para esclarecer suas dúvidas. Os dados citados apresentam-se a seguir no contexto da elaboração do trabalho.

Para elaborar o trabalho aqui apresentado, realizou-se as seguintes ações:

$1^{\circ}$ - análise do manual $-97,7 \%$

$2^{\circ}$ - pesquisa em bibliotecas $-92,0 \%$

$3^{\circ}$ - solicitação de esclarecimentos aos tutores $-86,4 \%$

$4^{\circ}$ - pesquisa na Net $-65,9 \%$

$5^{\circ}$ - busca de apoio com colegas $-63,6 \%$

$6^{\circ}$ - pedido de ajuda a outros profissionais $-42,0 \%$ 


\section{Considerações Finais}

O uso do texto Problemas e Projectos Educacionais foi sem dúvida muito importante para o desenvolvimento do projecto dos estudantes, mas somente este recurso não seria suficiente para que eles desenvolvessem os seus projectos de acordo com os objetivos do Seminário.

A análise dos dados apresentados corrobora com o estudo proposto pelo Seminário. Tem-se um longo caminho pela frente, iniciado com Seminários já realizados anteriormente e outros que estão a ocorrer. Nesse contexto, este artigo procurou apresentar uma pequena parte de um todo que está em desenvolvimento.

Um aspecto importante a salientar é que, apesar do destaque feito às mídias, o material impresso ainda tem espaço na educação a distância e que a coexistência entre novos e antigos recursos se configura como uma das tendências para os próximos anos.

Quando se pensa em educação a distância precisa-se pensar também quem são os estudantes, qual o seu perfil, a que e a quem se destina a proposta de trabalho mediada pelas mais ou menos sofisticadas tecnologias e com quais delas se pretende trabalhar, para que se possa melhor utilizar os diversos recursos disponíveis de apoio ao ensino e à aprendizagem.

As dificuldades são pontuais a partir do levantamento dos dados e o instrumento de recolha de dados. Foram entrevistados os tutores e estudantes no final do seminário.

Seja material impresso, telefone, email, fax, Internet, videoconferência, CDRom, televisão, rádio, etc., o que realmente importa é que um deles deve chegar até o estudante, pois o que se quer é promover um ensino de qualidade atendendo a todos sem discriminação de nenhum acesso à educação. A construção do conhecimento se dá a partir de qualquer recurso desde que eles cheguem até o estudante e que ele não fique isolado, esquecido ou ainda em silêncio. Nesse contexto, o apoio permanente do tutor/professor, sua interacção com seus alunos, por qualquer meio que seja, é fundamental para o acontecimento do Seminário ou de qualquer outro evento a distância. Tarouco(2003) corrobora dizendo que, ao tratar da questão da formação de professores para o século XXI, diz ser necessário preparar os professores para a inovação tecnológica e suas consequências, promovendo a formação continuada ao desenvolver competências na cultura técnica, na comunicação e na capacitação docente para o trabalho com método.

\section{Bibliografia}

AXT, Margarete. Tecnologia na educação, tecnologia para a educação - um texto em construção.Revista Informática na Educação: teoria \& prática, 3(1):51-52, Porto Alegre, UFRGS, 2000.

ARETIO, Garcia. La educación a distancia: de la teoria a la práctica. Barcelona, Ariel Educación, 2001.

. Educación a distancia. Hoy. Madrid: UNED, 1994

BACKTHIN, Michael. Estética da Criação Verbal.Martins Fontes : São Paulo, 2000. FARACO, Carlos Alberto. Linguagem e Diálogo. As idéias linguiísticas do círculo de Bakhtin. Paraná : Criar, 2003.

LANDIN, Cláudia M. M.P. Ferreira. Educação a Distância: algumas considerações. Rio de Janeiro : [s.n], 1997.

PEREIRA, Alda e MIRANDA, Branca. Problemas e Projectos Educacionais. Universidade Aberta, Lisboa, Portugal, 2003.

SILVA, Marco (org.) Educação Online. Teorias, Práticas, Legislação, Formação Coorporativa. Edições Loyola, 2003. 
TAROUCO, Liane M. R. Comportamentalismo e o computador como máquina de ensinar. Disponível em: <http://penta2.ufrgs.br/edu/edu3375/e3375m.htm> Acesso em: 21 de abr. 2003.

TAROUCO, Liane M.R. Formação de professores para o século XXI. Disponível em: $<$ http://www.cinted.ufrgs.br/ppt/forumespie2003/tsld002.htm> Acesso em: 01 de Jun, 2003. 